\title{
Studies on Process Standardization and Organoleptic Evaluation of Cereal based Probiotic Beverage
}

\author{
H.W. Deshpande ${ }^{1}$, S.N. Shendge ${ }^{2}$, S.D. Katke ${ }^{3 *}$ and A.P. Khapre ${ }^{4}$ \\ Department of Food Microbiology and Safety, College of Food Technology, \\ VNMKV, Parbhani, India \\ *Corresponding author
}

\section{A B S T R A C T}

Keywords

Non Dairy Probiotic

Beverage, Cereal

based Probiotic

Beverage, Cereal

Slurry Lactobacillus

acidophilus,

Bifidobacterium

bifidum

Article Info

Accepted:

10 January 2019

Available Online:

10 February 2019
The present investigation focuses on standardizing the process for preparation of cereal based probiotic beverage. A combination of barley slurry, sorghum slurry, garden cress seed powder and pumpkin seed powder was used for the preparation of probiotic beverage. The lactic acid fermentation with LAB starter culture containing Lactobacillus acidophilus and Bifidobacterium bifidum was carried out. The most acceptable probiotic beverage having $70 \mathrm{ml}$ barley slurry, $30 \mathrm{ml}$ sorghum slurry, 4 gm garden cress seed, 4 gm pumpkin seed powder and 3 percent starter culture with fermentation period of 4 hours was found to be most desirable in terms of sensorial quality profile. It has total energy value of $75.127 \mathrm{Kcal}$ and the shelf life of beverage was 9 days under refrigerator storage $\left(4^{\circ} \mathrm{C}\right)$. The process of preparation of cereal based probiotic beverage being a techno-economically feasible, justified the suitability of cereals in probiotic based functional food for commercial exploitation.

\section{Introduction}

"Probiotic" is used to refer to cultures of live microorganisms which, when administered to humans or animals, improve properties of indigenous microbiota. In the food industry, the term is described as "live microbial food ingredients that are beneficial to health" (Clancy, 2003). The term probiotic was technically defined by an Expert Committee as "live microorganisms which upon ingestion in certain numbers exert health benefits beyond inherent general nutrition'. Species of Lactobacillus and Bifidobacterium are most commonly used probiotics, but the Saccharomyces cerevisiae and Bacillus species are also used as a probiotics (Tomisik and Tomasik, 2003).

Recently, probiotics have been more widely defined as bacteria that work to maintain the host's health (Holzapfel, 2002; Saito, 2004; Grajek et al., 2005). Probiotics have some health benefits like they offers increased 
resistance to establishment of infection by potentially pathogenic organisms in the intestine, decreased duration of diarrhoea (antibiotic associated, travellers, infective), used in lactose intolerance (promotion of intestinal lactose digestion). increased nutritional value (better digestibility, increased absorption of vitamins and minerals), regulation of gut motility (constipation, irritable bowel syndrome), maintenance of mucosal integrity of the intestine, reduction in serum cholesterol concentration, reduction in allergy, prevention of colon cancer, reduction in carcinogen production etc. (Orrhage and Nord, 2000). Associated with probiotics are prebiotics. Prebiotics are non-digestible food ingredients that have a beneficial effect on the host by selectively stimulating growth of healthpromoting bacteria (Desai et al., 2004). They are assimilated by beneficial bacteria such as Bifidobacteria hence improving their growth activity leading to an enhanced intestinal balance. For a food to qualify as a prebiotic, it: has to be non-digestible by human enzymes; has to undergo selective fermentation by potentially beneficial bacteria in the colon; should cause an alteration in the composition of the colonic microbiota towards a healthier composition and all these changes should lead to a beneficial health to the host (Pariyaporn et al., 2003). Some researches with prebiotics have reported reduction in putative risk factors for colon cancer and control of serum triglycerides as well as cholesterol (Roberfroid, 2001).

Most probiotic foods available today are milk based, but consumer preference today lie more with botanical dietary supplements, which are either free from or have minimal cholesterol content. Also, the market for functional foods is in its infancy in many countries; however, product innovation throughout a number of sectors, such as drinks, bakery and probiotics, is evident, with trends generally following those of the U.S and U.K. (Luckow and Delahunty, 2004). With an increase in the consumer vegetarianism throughout the developed countries, there is also a demand for the vegetarian probiotic products. Furthermore, lactose intolerance and the cholesterol content are two major drawbacks related to the fermented dairy products.

There are a wide variety of traditional nondairy fermented beverages produced around the world. Much of them are non-alcoholic beverages manufactured with cereals as principal raw material. Studies may be classified based on the source of raw material for the production of the non dairy probiotic beverage (Heenan et al., 2004). The cereal products often ferment spontaneously, resulting in improved shelf life and better nutritional properties compares with raw materials. Fermentation procedures have been used to develop new foods with enhanced health properties (Blandino et al., 2003).

Cereal grains are an important source of protein, carbohydrates, vitamins, minerals and fiber for people all over the world, and can be used as sources of non-digestible carbohydrates that besides promoting several beneficial physiological effects can also selectively stimulate the growth of Lactobacilli and Bifidobacteria present in the colon, thereby acting as prebiotics (Manthey et al., 1999, Wood and Beer, 1998).

Cereals contain water-soluble fiber (such as $\beta$-glucan and arabinoxylan), oligosaccharides (such as galacto and fructo oligosaccharides) and resistant starch, and thus have been suggested to fulfil the prebiotic concept (Andersson et al., 2001). The whole barley grain consists of about 65-68\% starch, 10$17 \%$ protein, $4-9 \%$, $\beta$-glucan, $2-3 \%$ free lipids, $1.5-2.5 \%$ minerals, $11-34 \%$ total dietary fibers and 3 to $20 \%$ soluble dietary 
fiber (Quinde et al., 2004). According to USDA, (2010) sorghum is an excellent source of energy, containing about $75 \%$ complex carbohydrates (fibers and starches) which are usually digested slowly and therefore provide satiety and delayed hunger.

The pumpkin seeds were found to be rich in oil $50 \%, 38 \%$ protein and $3 \mathrm{~g} / 100 \mathrm{~g} \alpha-$ tocopherols (Younis et al., 2000). The garden cress seed contains $34.15 \%$ protein, $1.86 \%$ crude oil, 9.85\%crude fiber, $5.89 \%$ ash and $48.25 \%$ nitrogen free extract (NFE), on a dry weight basis (Gaafar et al., 2013).

The beneficial effects of food with added live microbes (probiotics) on human health are being increasingly promoted by health professionals. Probiotic products available in the markets today, are usually in the form of fermented milks and yoghurts; however, with an increase in the consumer vegetarianism throughout the developed countries, there is also a demand for the vegetarian probiotic products.

\section{Materials and Methods}

Sorghum, barley, pumpkin seeds and garden cress seeds, sugar were collected from local market

\section{Preparation of starter culture}

The starter culture was prepared with the help of the method described by Ghadge et al., (2008) with some modifications.

\section{Composition of MRS medium}

All the ingredients were suspended in distilled water and heated to dissolve the medium completely. The medium was sterilized in autoclave at $15 \mathrm{lbs}$ pressure for 15 minutes (De Mann et al., 1960) (Table 1).
Isolation of lactic acid bacteria from the commercial yoghurt sample

The sample of yoghurt was used for isolation of culture on MRS agar. The serially diluted sample was inoculated on MRS agar and incubated at $37^{\circ} \mathrm{c}$ for 24 hours. Then selected colonies were again inoculated in to MRS broth for 24-48 hours. After vigorous growth of culture then again inoculated and incubated on MRS agar to get pure culture. This culture was grown on nutrient agar by standard procedure.

\section{Purity of the cultures}

The staining of the obtained pure cultures of Lactobacillus acidophilus and Bifidobacterium bifidum was carried out by using Gram positive staining technique for their identification (Harley and Prescott, 2002) (Table 2).

\section{Sub-culturing of pure culture}

The pure cultures i.e. Lactobacillus acidophilus and Bifidobacterium bifidum were sub-cultured on slants prepared from MRS media in laminar air flow. This was incubated at $37^{\circ} \mathrm{C}$ for 24 hours in incubator. It is having microbial count nearly about $32 \mathrm{x}$ $10^{7} \mathrm{cfu} / \mathrm{ml}$.

\section{Preparation of Probiotic cereal beverage}

The production of probiotic cereal beverage was carried out by using Lactobacillus acidophilus and Bifidobacterium bifidum starter culture. The recipe used for preparation of cereal based probiotic beverage are mentioned below in Table 4 and the three standard compositions of composite flour are represented in Table 3 and pure LAB cultures used in recipe in different concentration is mentioned in Table 5. 
Int.J.Curr.Microbiol.App.Sci (2019) 8(3): 1073-1086

\section{Preparation of starter culture}

\section{Stock bacterial cultures}

(Lactobacillus acidophilus and Bifidobacterium bifidum)

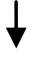

Activation of bacterial strains in MRS broth separately at $37^{\circ} \mathrm{C}$ for $48 \mathrm{hr}$

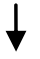

Starter culture Containing L. acidophilus and B. bifidum in equal proportions

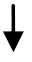

Centrifugation at $4000 \mathrm{rpm}$ for $7 \mathrm{~min}$

Starter culture

\section{Preparation of Barley Slurry}

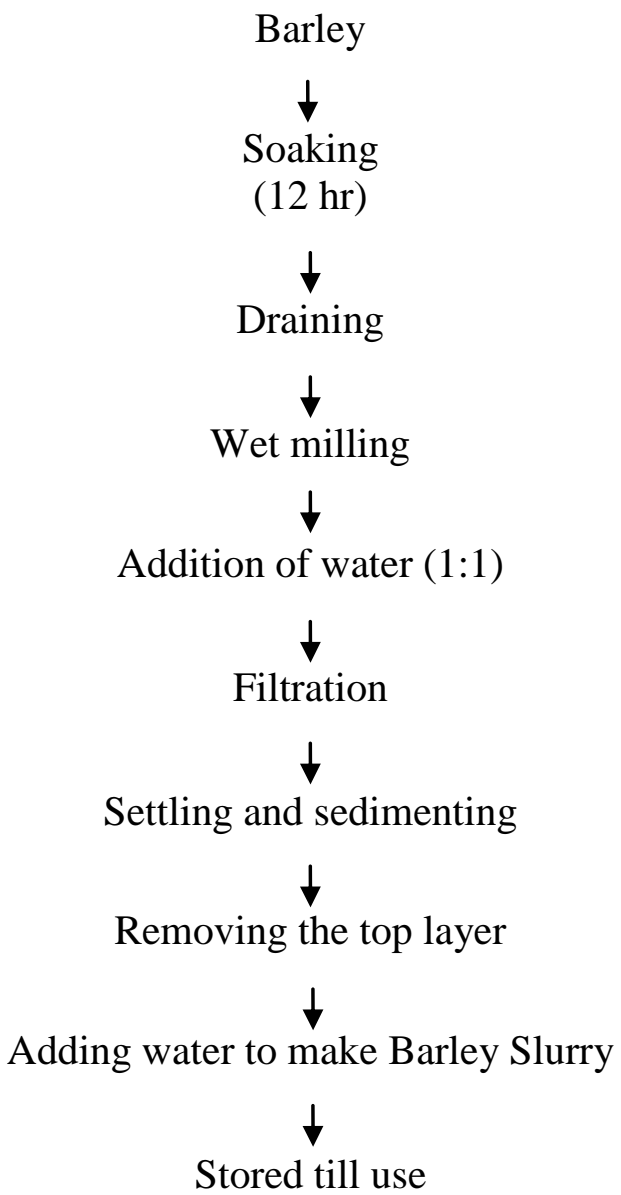




\section{Preparation of Sorghum Slurry}

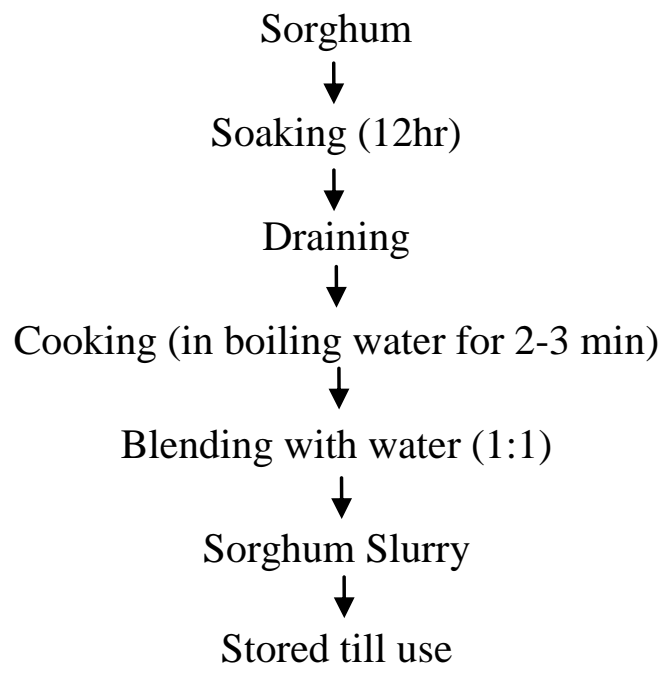

Preparation of Cereal Based Probiotic Beverages

Barley and Sorghum slurry (as per selected composition)

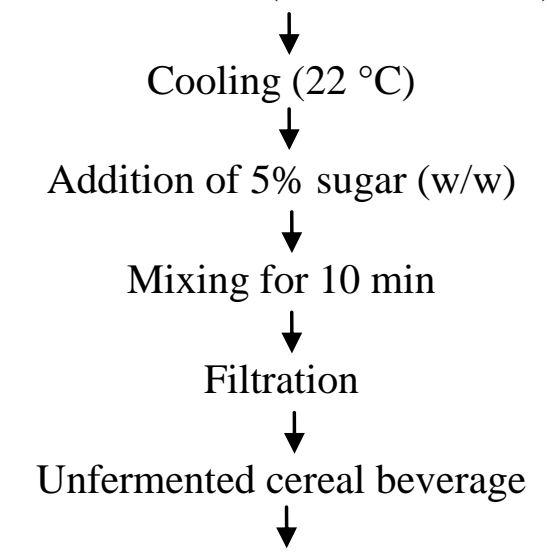

Inoculation with $3 \%$ starter culture (L. acidophilus and Bifidobacterium bifidum) (containing equal amount of LAB culture, having initial conc. of cells $32 \times 10^{7} \mathrm{cfu} / \mathrm{ml}$ )<smiles>[13CH3]</smiles>

Fermentation $\left(37^{\circ} \mathrm{C}\right.$ for $\left.4 \mathrm{hr}\right)$

$\downarrow$

(Pumpkin seed powder $2 \%) \rightarrow$ Plain beverage $\leftarrow$ (Garden Cress seed powder $2 \%)$

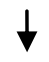

Probiotic cereal beverage

$\downarrow$

Packing in PET bottle and storage $\left(4^{\circ} \mathrm{C}\right)$ 


\section{Results and Discussion}

\section{Proximate composition of raw material}

The proximate composition of raw material is depicted in Table 6.

The data presented in Table 6 revealed that highest moisture content was observed in barley (12.3\%) followed by sorghum (10.41\%), pumpkin seed $(7.43 \%)$ whereas lowest moisture content was recorded in garden cress seed $(5.15 \%)$. Highest protein content was recorded in pumpkin seed $(29.12 \%)$ whereas lowest protein was observed in barley (10.6\%). It could be observed that highest fat content was recorded in pumpkin seeds $(27.83 \%)$ whereas lowest value was recorded for barley (2.6\%). Highest ash content was recorded for garden cress seeds $(4.65 \%)$ whereas lowest ash was observed in sorghum $(1.18 \%)$. Highest value of crude fibre was recorded in pumpkin seeds $(12.3 \%)$ whereas lowest value was recorded in sorghum (1.3\%). It could be observed that cereal grains had higher carbohydrate content than the pumpkin seeds and garden cress seeds. Highest value was recorded in sorghum $(65.72 \%)$ whereas lowest was recorded in pumpkin seeds $(22.21 \%)$. Similar results were obtained by Belitz et al., (2009); Doke and Guha, (2014).

\section{Sensory evaluation of cereal based probiotic beverage}

The obtained mean score values for sensorial characteristics of beverage are summarized in Table 7.

It is evident from the Table 7 that among various sensory characteristics color, flavor and taste were significantly affected by the various levels of addition of starter culture i.e. Lactobacillus acidophilus and Bifidobacterium bifidum ranging from 3 to 4 per cent and its incubation time period 4 to 5 hr. The results presented in Table 7 showed that the color of beverage was found to get lighter with increase in concentration of LAB starter culture and acceptable color was observed in Sample A and containing 3 per cent of Lactobacillus acidophilus and Bifidobacterium bifidum starter culture. The maximum score for color of beverage in treated sample was obtained by Sample A (i.e. 9.0). The scores assigned to flavor of beverage ranged from 8.4 to 9.0 among the beverage with highest score for Sample A. The taste (sourness) was found to increase with increase in concentration of culture. Maximum score for 'taste' was noted in the Sample A followed by C, while the B Sample scored the lowest value. Textural properties of all Samples were found to be increase with addition of starter culture. The beverage Samples added with starter culture are more viscous than control. Maximum textural score (i.e. 8.6) was secured by Sample A. The maximum score (i.e. 8.8) for overall acceptability was observed in Sample A having 70 per cent barley and 30 per cent sorghum and 3\% Lactobacillus acidophilus and Bifidobacterium bifidum starter culture while the minimum score (i.e. 8.3) was observed in control Sample B.

\section{Physicochemical analysis of cereal based probiotic beverage}

As sample A containing 65 per cent barley in composite flour and 27 per cent sorghum flour and 3 per cent of Lactobacillus acidophilus and Bifidobacterium bifidum starter culture had shown maximum consumer acceptability as observed through sensory evaluation of all Samples. Sample A was selected for further studies. The obtained results for various parameters are presented in Table 8 .

From the results presented in Table 8, it has been observed that the $\mathrm{pH}$, Titratable acidity, total solids and viscosity of accepted beverage 
Sample were found to be $4.01,0.44$ per cent, 14.67 per cent and 35 centipoises respectively. Decrease in $\mathrm{pH}$ might be due to the less acidic nature of pumpkin seeds and garden cress seeds. These results are also corroborated with findings of Salwa and Diekmann, (2000).

Proximate composition of cereal based probiotic beverage

The proximate composition of cereal based probiotic beverage is depicted in Table 9 .

Data presented in Table 9 revealed that the beverage Sample contained 81.28 per cent moisture, 3.43 per cent crude protein. Higher protein content in probiotic beverage might be might be due to the protein content presented in pumpkin seed powder and garden cress seeds. It was observed that ash content of probiotic Sample was 1.270 percent. Ash content increased significantly due to fermentation process and fortification with pumpkin and garden cress seed. It was observed that fat content of probiotic beverage was 1.823 per cent. It was increased due to the fortification of pumpkin seed powder and garden cress seeds. It was observed that the carbohydrate content of prepared probiotic beverage was 11.25 per cent.

Effect of storage period on physicochemical properties of cereal based probiotic beverage

The prepared probiotic beverage sample was further analyzed for physicochemical properties during storage up to 9 days. The data regarding the physicochemical properties of prepared probiotic beverage sample are presented in Table 10.

The data represented in Table 10 revealed that the $\mathrm{pH}$ of accepted beverage Sample was found to be 4.08, 3.98, 3.83, and 3.80 on the day of preparation, third, sixth, and ninth days after production respectively. It could be observed that the Titratable acidity of Sample increased during storage period. During storage period, the acidity values of the beverage Sample significantly increased from 0.30 per cent to 0.47 per cent from the day of preparation until the nine days of storage. It could be observed that the viscosity of the prepared probiotic beverage Sample increased with the storage. The viscosity of fresh beverage Sample was $36 \mathrm{cP}$ at $25^{\circ} \mathrm{C}$ whereas it was increased to $43 \mathrm{cP}$ at $25^{\circ} \mathrm{C}$ on $9^{\text {th }}$ day of storage. It could be observed that the Titratable acidity of the Sample was 0.30 per cent on the day of preparation, 0.39 on third day of storage, 0.42 per cent on sixth day and 0.47 per cent on $9^{\text {th }}$ day of storage. Data indicated that the storage time significantly affected the acidity level in the probiotic cereal beverage; Titratable acidity increased, while the $\mathrm{pH}$ was decreased. The positive change in Titratable acidity and negative change in $\mathrm{pH}$ level was due to the ongoing multiplication of LAB during storage period. These results are in agreement with those reported by Tangular and Erten (2012).

\section{Measurement of textural (consistency) properties of cereal based probiotic beverage}

The viscosity of different samples of cereal based probiotic beverage was calculated on Brookfield Viscometer DVE at constant speed $100 \mathrm{rpm}$ with a spindle number S-63 at different temperatures i.e. at $30,32,34$ and $36^{\circ} \mathrm{C}$ and expressed in terms of centipoises $(\mathrm{cP})$. The results obtained regarding the consistency of probiotic beverage are presented in Table 11.

The data presented in Table 11 revealed that the viscosity of the beverage decreased with increase in temperature. 
Table.1 Composition of MRS media for LAB culture

\begin{tabular}{|l|c|c|}
\hline \multicolumn{1}{|c|}{ Ingredients (g) } & L. acidophilus & B. bifidum \\
\hline Proteose peptone & 10 & 10 \\
\hline Yeast extract & 5.0 & 5.0 \\
\hline Beef extract & 10 & 10 \\
\hline Dextrose & 20 & 20 \\
\hline Tween-80 & 1.0 & 1.0 \\
\hline Ammonium citrate & 2.0 & 2.0 \\
\hline Sodium acetate & 5.0 & 5.0 \\
\hline Magnesium sulphate & 0.1 & 0.1 \\
\hline Manganese sulphate & 0.5 & 0.5 \\
\hline $\begin{array}{l}\text { Di-potassium } \\
\text { phosphate }\end{array}$ & 2.0 & 2.0 \\
\hline Distilled water (lit) & 1.0 & 1.0 \\
\hline L.cysteine & - & 0.5 \\
\hline
\end{tabular}

Table.2 Confirmation tests for Lactobacillus acidophilus and B. bifidum

\begin{tabular}{|l|c|c|}
\hline \multicolumn{1}{|c|}{ Biochemical test } & Lactobacillus acidophilus & B. bifidum \\
\hline Morphology & Rod, pair, chain & Y shape \\
\hline Gram staining & $+\mathrm{ve}$ & $-\mathrm{ve}$ \\
\hline Catalase test & $-\mathrm{ve}$ & $-\mathrm{ve}$ \\
\hline
\end{tabular}

Table.3 Standardization of composite flour

\begin{tabular}{|l|c|c|c|c|}
\hline Grain Flour & Sample A (g) & Sample B (g) & Sample C (g) & Control (g) \\
\hline Barley & 65 & 55 & 46 & 100 \\
\hline Sorghum & 27 & 37 & 46 & 0 \\
\hline Pumpkin & 4.0 & 4.0 & 4.0 & 0 \\
\hline Garden cress & 4.0 & 4.0 & 4.0 & 0 \\
\hline
\end{tabular}

Table.4 Standard recipe for preparation of cereal based probiotic beverage

\begin{tabular}{|l|c|}
\hline \multicolumn{1}{|c|}{ Ingredient } & Quantity (g) \\
\hline Composite flour & 100 \\
\hline Sugar & 5 \\
\hline Garden cress seed & 4 \\
\hline Pumpkin seed powder & 4 \\
\hline Water (liter) & 1 \\
\hline
\end{tabular}


Table.5 Various levels of addition of starter culture at different Incubation period

\begin{tabular}{|c|c|c|c|c|}
\hline \multirow{2}{*}{ Sample } & \multicolumn{2}{|c|}{ Starter Culture Concentration (\%) } & \multicolumn{2}{|c|}{ Time (hr) } \\
\cline { 2 - 4 } & L. acidophilus & B. bifidum & \multicolumn{2}{|c|}{} \\
\hline Control & 3 & 4 & 3 & 4 \\
\hline A & 3 & 4 & 3 & 4 \\
\hline B & 3 & 4 & 3 & 4 \\
\hline C & 3 & 4 & 3 & 4 \\
\hline
\end{tabular}

Table.6 Proximate composition of raw material

\begin{tabular}{|l|c|c|c|c|c|c|}
\hline \multicolumn{1}{c}{$\begin{array}{c}\text { Cereal } \\
\text { Grain }\end{array}$} & $\begin{array}{c}\text { Moisture } \\
(\mathbf{\%})\end{array}$ & $\begin{array}{c}\text { Crude } \\
\text { Protein (\%) }\end{array}$ & $\begin{array}{c}\text { Crude } \\
\text { Fat (\%) }\end{array}$ & $\begin{array}{c}\text { Ash } \\
(\mathbf{\%})\end{array}$ & $\begin{array}{c}\text { Crude } \\
\text { Fiber (\%) }\end{array}$ & $\begin{array}{c}\text { Total } \\
\text { Carbohydrates (\%) }\end{array}$ \\
\hline Barley & 12.3 & 10.6 & 2.6 & 2.1 & 9.5 & 62.01 \\
\hline Sorghum & 10.41 & 11.1 & 3.1 & 1.18 & 1.3 & 65.72 \\
\hline Pumpkin Seeds & 7.43 & 29.12 & 27.83 & 4.1 & 12.3 & 22.21 \\
\hline $\begin{array}{l}\text { Garden Cress } \\
\text { Seeds }\end{array}$ & 5.15 & 21.47 & 2.78 & 4.65 & 6.8 & 34.24 \\
\hline SE & & & & & & \\
\hline CD at 5\% & 0.06954 & 0.03716 & 0.03653 & 0.00192 & 0.00319 & 0.00167 \\
\hline
\end{tabular}

Table.7 Sensory evaluation of cereal based probiotic beverage using hedonic scale

\begin{tabular}{|c|c|c|c|c|c|}
\hline Sample & Color & Flavor & Taste & Texture & $\begin{array}{c}\text { Overall } \\
\text { acceptability }\end{array}$ \\
\hline Control & 8.8 & 8.4 & 8.6 & 8.2 & 8.5 \\
\hline $\mathbf{A}$ & 9.0 & 9.0 & 8.8 & 8.6 & 8.8 \\
\hline B & 8.2 & 8.4 & 8.5 & 8.3 & 8.3 \\
\hline C & 8.6 & 8.5 & 8.6 & 8.4 & 8.5 \\
\hline SE & 0.05963 & 0.09129 & 0.05963 & 0.05963 & 0.06393 \\
\hline CD at 5\% & 0.17889 & 0.27124 & 0.17717 & 0.17717 & 0.18996 \\
\hline
\end{tabular}

Table.8 Physicochemical characteristics of cereal based probiotic beverage

\begin{tabular}{|l|c|}
\hline \multicolumn{1}{|c|}{ Parameter } & Values (\%) \\
\hline pH & 4.01 \\
\hline T.S.S ( $\left.{ }^{\mathbf{0}} \mathbf{B x}\right)$ & 14.67 \\
\hline Viscosity (cP) & 35 \\
\hline Titrable Acidity (\%) & 0.4 \\
\hline
\end{tabular}


Table.9 Proximate analysis of cereal based probiotic beverage

\begin{tabular}{|l|c|}
\hline \multicolumn{1}{|c|}{ Parameter } & Values (\%) \\
\hline Moisture & 81.28 \\
\hline Crude fat & 1.823 \\
\hline Crude protein & 3.43 \\
\hline Ash & 1.270 \\
\hline Total Carbohydrate & 11.25 \\
\hline
\end{tabular}

Table.10 Physicochemical properties of probiotic beverage during storage

\begin{tabular}{|c|c|c|c|}
\hline $\begin{array}{c}\text { Storage } \\
\text { (Days) }\end{array}$ & $\mathbf{p H}$ & $\begin{array}{c}\text { Titrable Acidity } \\
(\mathbf{\%})\end{array}$ & $\begin{array}{c}\text { Consistency at } \mathbf{2 5}^{\mathbf{0}} \mathbf{C} \\
(\mathbf{c P})\end{array}$ \\
\hline $\mathbf{0}$ & 4.08 & 0.30 & 36 \\
\hline $\mathbf{3}$ & 3.98 & 0.39 & 37 \\
\hline $\mathbf{6}$ & 3.83 & 0.42 & 40 \\
\hline $\mathbf{9}$ & 3.80 & 0.47 & 43 \\
\hline SE $\mathbf{\pm}$ & 0.012 & 0.006 & 0.06393 \\
\hline CD at 5\% & 0.036 & 0.019 & 0.18996 \\
\hline
\end{tabular}

Table.11 Textural (consistency) properties of cereal based probiotic beverage

\begin{tabular}{|c|c|c|c|c|}
\hline \multirow{2}{*}{$\begin{array}{c}\text { Temperature } \\
(\mathbf{0} \mathbf{C})\end{array}$} & \multicolumn{4}{|c|}{ Consistency (cP) } \\
\cline { 2 - 5 } & Control & A & B & C \\
\hline $\mathbf{3 0}$ & 33 & 35 & 40 & 43 \\
\hline $\mathbf{3 2}$ & 31 & 34 & 38 & 39 \\
\hline $\mathbf{3 4}$ & 28 & 32 & 35 & 37 \\
\hline $\mathbf{3 6}$ & 25 & 29 & 33 & 35 \\
\hline
\end{tabular}

Table.12 Microbial analysis of probiotic beverage during storage

\begin{tabular}{|c|c|c|c|}
\hline $\begin{array}{c}\text { Storage } \\
\text { (Days) }\end{array}$ & $\begin{array}{c}\text { Total Plate Count } \\
(\mathbf{c f u} / \mathbf{g m}) \mathbf{x} \mathbf{1 0}^{\mathbf{6}}\end{array}$ & $\begin{array}{c}\text { Yeast and Mold Count } \\
(\mathbf{c f u} / \mathbf{g m}) \mathbf{x} \mathbf{1 0}^{\mathbf{6}}\end{array}$ & Coliform Count \\
\hline $\mathbf{0}$ & 19 & 17 & Absent \\
\hline $\mathbf{3}$ & 23 & 11 & Absent \\
\hline $\mathbf{6}$ & 29 & 9 & Absent \\
\hline $\mathbf{9}$ & 33 & 4 & Absent \\
\hline
\end{tabular}


Table.13 Theoretical energy value of probiotic beverage

\begin{tabular}{|l|c|}
\hline \multicolumn{1}{|c|}{ Parameter } & Energy Value (Kcal) \\
\hline Carbohydrate & 45.00 \\
\hline Protein & 13.72 \\
\hline Crude Fat & 16.407 \\
\hline Total Energy & 75.127 \\
\hline
\end{tabular}

Graph.1 Sensory evaluation of cereal based probiotic beverage

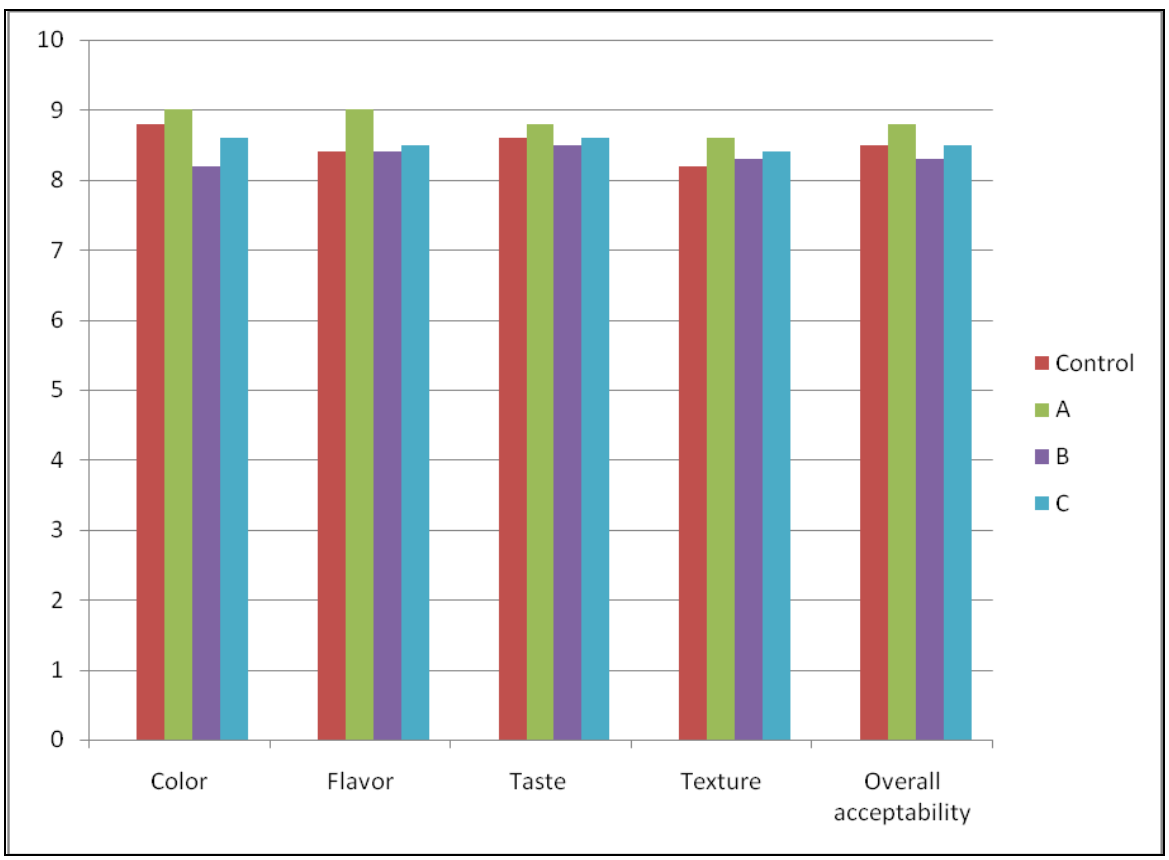

Graph.2 $\mathrm{pH}$ and titratable acidity of accepted probiotic beverage during storage

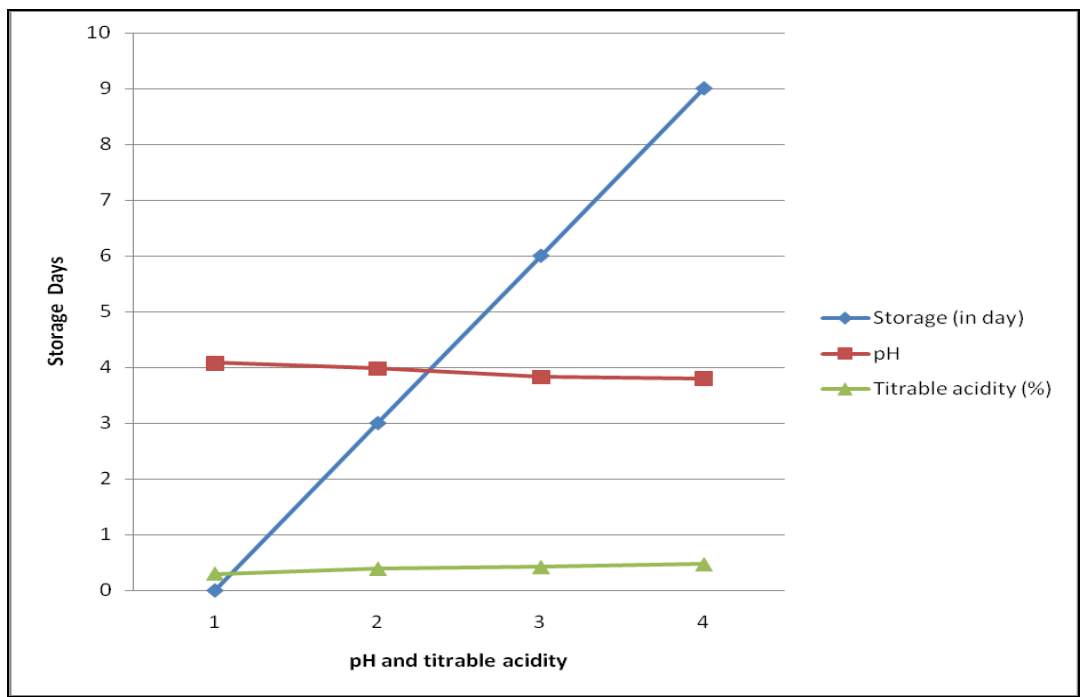


Graph.3 Effect of temperature on viscosity of accepted probiotic beverage

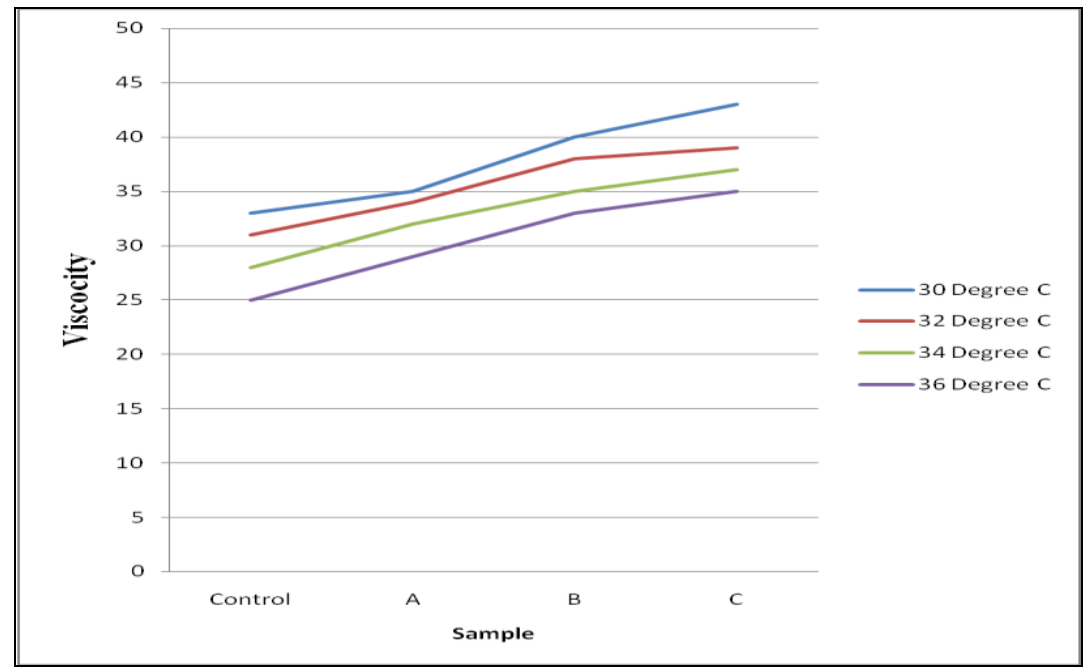

Viscosity of the Sample C is highest i.e. $43 \mathrm{cP}$ at temperature $30^{\circ} \mathrm{C}$ and it decreased as temperature increased and Control Sample showed least viscosity at $36^{\circ} \mathrm{C}$ i.e. $25 \mathrm{cP}$. Control Sample had lowest viscosity among all the other Samples i.e. $33 \mathrm{cP}$ at temperature $30^{\circ} \mathrm{C}$ which decreased with increased in temperature and recorded $25 \mathrm{cP}$ viscosity at $36^{\circ} \mathrm{C}$ temperature. It can be observed that addition of sorghum resulted in increase in the viscosity of the probiotic beverage. The decreased in acceptability of $\mathrm{B}$ and $\mathrm{C}$ as compared to control and A could be attributed to increased viscosity contributing to poor mouth feel of the probiotic beverage. Similar results were observed by Hasan et al.,(2012).

\section{Microbial analysis of cereal based probiotic} beverage during storage

The accepted beverage Sample was subjected to microbial studies for total plate count, yeast and mold count and Coliform growth during the storage period as per method adopted by Cappuccino and Sherman, (1996). The results recorded during the present investigation are presented in Table 12.

It is evident that the total plate count was the highest $\left(33 \times 10^{6}\right)$ in beverage after 9 days of storage period. However, the total plate count was lowest $\left(19 \times 10^{6}\right)$ in beverage Sample on production day. Total plate Counts (TPC) were high ranging from $19 \times 10^{6} \mathrm{cfu} / \mathrm{g}$ at zero time and reached $33 \times 10^{6} \mathrm{cfu} / \mathrm{g}$ at the end of storage period. Data presented in Table 11 indicated that the total plate counts of accepted beverage Sample is $19 \times 10^{6}, 23 \times 10^{6}$, $29 \times 10^{6}$ and $33 \times 10^{6} \mathrm{cfu} / \mathrm{g}$ for the Sample on day of production, third, sixth and ninth days after production respectively. Maximum numbers of yeast and mold colonies were recorded in Sample on the day of production $\left(17 \times 10^{6}\right)$. However, the fungal count was lowest $\left(4 \times 10^{6}\right)$ in Sample after 9 days of storage period. From the Table 11 it is also observed that the yeast and mold counts of accepted beverage Sample is $17 \times 10^{6}, 11 \times 10^{6}$, $9 \times 10^{6}$ and $4 \times 10^{6} \mathrm{cfu} / \mathrm{ml}$ for the Sample on day of production, third, sixth and ninth days after production respectively. The results showed that addition of lactic acid starter culture in beverage was effective in enhancing the shelf life of beverage by inhibiting mold growth. The results from Table also shows that, the beverage Sample was free from Coliform and E. coli when the Sample was fresh and throughout the storage period (of 9 days) at refrigerator temperature of $4^{\circ} \mathrm{C}$ as result of good hygienic and sanitary conditions, during 
the preparation of cereal based probiotic beverage.

A minimum of $10^{6}-10^{7}$ plate microorganisms per gram or milliliter should be present in food product in order to meet the requirements of a probiotic food, as by the Japanese Fermented Milk and Lactic Acid Bacteria Beverages Association (Ishibashi and Shimanura, 1993).

\section{Theoretical energy value of prepared cereal based probiotic beverage}

The energy value of prepared probiotic beverage Sample is presented in Table 13.

It is evident from the Table 13 that the total energy value of the probiotic cereal beverage is $75.127 \mathrm{Kcal}$ as calculated by adding energy value obtained from crude protein, crude fat and total carbohydrates.

Hence concluded, thus in light of scientific data of the present investigation, it may be concluded that the most acceptable probiotic beverage i.e. sample "A" having $70 \mathrm{ml}$ barley slurry, $30 \mathrm{ml}$ sorghum slurry, $4 \mathrm{~g}$ garden cress seed, $4 \mathrm{~g}$ pumpkin seed powder and 3 per cent starter culture with fermentation period of 4 hours was found to be most desirable in terms of sensorial quality profile of health food. The shelf life of beverage is calculated (9 days) under refrigerator storage $\left(4^{\circ} \mathrm{C}\right)$.

\section{References}

Andersson H., Asp N. G., Bruce A., Roos S., Wadstrom T. and Wold A. E. (2001). Health effects of probiotics and prebiotics: A literature review on human studies. Journal of Nutrition, 45: 58-75.

Belitz H. D., Grosch W. and Schieberle P. (2009). Cereals and cereal products. Food chemistry, 4th edition, 670-675.
Blandino A., Al-Aseeri M. E., Pandiella S. S., Cantero D. and Webb C. (2003). Cereal based fermented foods and beverages. Food Research International Journal, 36: 527-543.

Cappuccino J. G. and Sherman N. (1996). Microbiology: a laboratory manual. The Benjamin / cummings publication, Co. Inc. NY.

Clancy R. (2003). Immunobiotics and the probiotic evolution. FEMS Immunology and Medical Microbiology, 38(1): 9-12.

De Mann J. C., Rogosa M. and Sharpe M. E. (1960). A medium for the cultivation of Lactobacilli. Journal of Applied Bacteriology, 23(1): 130-135.

Desai A. R., Powel I. B. and Shah N.P. (2004). Survival and activity of probiotic Lactobacilli in skim milk containing prebiotics. Journal of Food Science, 69(3): 57-60.

Doke S. and Guha M. (2014). Garden cress (Lepidium sativum l.) seed - an important medicinal source: a review. Journal of Natural Prod. Plant Resources, 4(1): 69-80.

Gaafar A. M., Morsi A. A. and Elghamry H. E. (2013). Chemical, nutritional and biochemical studies of garden cress protein isolate. Nature and Science, 11(2): 8-13.

Ghadge P. N., Prasad K., and Kadam P. S. (2008). Effect of fortification on the physic- chemical and sensory properties of buffalo milk yoghurt. Electronic Journal of Environmental Agriculture of Food Chemistry, 7(5): 2890-2899.

Grajek W, Olejnik A and Sip A. (2005). Probiotics, prebiotics and antioxidants as functional foods. Acta Biochimica Polonica, 52(3): 665-671.

Harley J. P. and Prescott L. M. (2002). Bacterial morphology and staining. Laboratory Exercises in Microbiology, Fifth Edition, Mcgraw-Hill Publishing Company Limited. 
Harrigan C. and McCance P. (1966). Laboratory Methods in microbiology, Academic press, New York.

Hassan A. A., Aly M. M. and El-Hadidie S. T. (2012). Production of Cereal-Based Probiotic Beverages. World Applied Sciences Journal, 19 (10): 1367-1380.

Heenan C. N., Adams M. C., Hosken R. W. and Fleet G. H. (2004). Survival and sensory acceptability of probiotic microorganisms in a non fermented frozen vegetarian dessert. LebensmittelWissenschaft und-Technology, 37(4): 461- 466.

Holzapfel W. H. (2002). Appropriate starter culture technologies for small scale fermentation in developing countries. International Journal of Food Microbiology, 75: 197-212.

Ishibashi N. and Shimanura S. (1993). Bifidobacteria: research and development in Japan. Food Technology, 47(6): 126-135.

Luckow T. and Delahunty C. (2004). A consumer study of probiotic non-dairy juice drinks. Food Quality and Preference, 15(7): 751-759.

Manthey F. A. Hareland G. A. and Huseby D. J. (1999). Soluble and insoluble dietary fibre content and composition in oat. Cereal Chemistry, 76(3): 417-420.

Orrhage K. and Nord C. E. (2000). "Bifidobacteria and Lactobacilli" in human health and other colonic bacteria. Journal of Applied Bacteriology,77(4): 412-20.

Pariyaporn I., Khawla S. H. and Robinson R K. (2003). The potential therapeutic benefits of consuming 'health promoting' fermented dairy products: a brief update. International Journal of Dairy Technolology, 56(4): 203-210.

Quinde Z., Ullrich S. E. and Baik B. K. (2004).Genotypic variation in colour and discolouration potential of barleybased food products. Cereal Chemistry, 81(6): 752-758.

Roberfroid M. B. (2001). Prebiotics: preferential substrates for specific germs. American Journal of Clinical Nutrition, 7 (2): 406-409.

Saito T. (2004). Selection of useful probiotic lactic acid bacteria from Lactobacillus acidophilus group and their application to functional foods. Animal Science Journal, 75(1): 1-13.

Salwa A. A. and Diekmann H. (2000). Behavior of aflatoxin during manufacture and storage of yoghurt. Alex. Journal of Veterinary Science, 16(1): 1-7.

Tangular H. and Erten H. (2012). Occurrence and growth of lactic acid bacteria species during the fermentation of shalgam (salgam), a traditional Turkish fermented beverage. LWT- Food Science and Technology, 46(1): 36-41.

Tomsik P. J. and Tomasik P.(2003). Probiotics and Prebiotics. Cereal Chem. 80(2): 113- 117.

USDA. (2010). Report of the Dietary Guidelines Advisory Committee on the Dietary Guidelines for Americans.

Younis Y. M., Ghirmay S and Al-Shihry S. S. (2000). African Cucurbitapepo L.: properties of seed and variability in fatty acid composition of seed oil. Phytochemistry, 54(1): 71-75.

\section{How to cite this article:}

Deshpande, H.W., S.N. Shendge, S.D. Katke and Khapre, A.P. 2019. Studies on Process Standardization and Organoleptic Evaluation of Cereal based Probiotic Beverage. Int.J.Curr.Microbiol.App.Sci. 8(03): 1073-1086. doi: https://doi.org/10.20546/ijcmas.2019.803.130 